\title{
Growth of Wheat Genotypes Influenced by Heat Stress
}

\author{
Pronay Bala ${ }^{*}$, Sritati Sikder ${ }^{2}$ \\ ${ }^{1}$ Assistant Professor, Department of Agriculture, Hazi Lalmia City College, Gopalganj,Bangladesh \\ ${ }^{2}$ Professor, Department of Crop Physiology and Ecology, Hajee Mohammad Danesh Science and Technology University, \\ Dinajpur, Bangladesh.
}

\begin{abstract}
Effect of heat stress on growth of eight wheat genotypes was evaluated. Total dry matter (TDM), leaf area index (LAI), crop growth rate (CGR) and net assimilation rate (NAR) were lower at the initial stage of growth and increased with plant age and all the genotypes showed higher values at normal growing condition compared to late and very late growing condition in both the years. Growth attributes such as LAR for all the genotypes declined throughout the advancement of growth stages in each growing conditions of both years. The HT genotypes showed higher values of TDM, LAI, CGR and LAD compared to MHS and HS genotypes in both the years.
\end{abstract}

Keywords-Crop growth rate, Heat stress, Leaf area index, Total dry matter Wheat.

\section{INTRODUCTION}

Wheat (Triticum aestivum L.) is a thermo sensitive cool season crop. But it is extensively cultivated in the world with latitudinal distribution from $30-60^{\circ} \mathrm{N}$ and $27-40^{\circ} \mathrm{S}$. The optimum temperature for wheat is $15-18^{\circ} \mathrm{C}[1]$ while moderate high temperature $\left(23-32^{\circ} \mathrm{C}\right)$ for longer duration and very high temperature $\left(33-40^{\circ} \mathrm{C}\right)$ for a shorter period are very common in the Mediterranean and subtropical environments particularly during grain filling [2]. Globally, about seven million hectares of wheat is affected by heat stress through the life cycle and about $40 \%$ crop faces terminal heat stress [3]. However, in some parts of Asian subcontinent where CIMMYT wheat germplasm has been successfully utilized, late planting is very common due to wide spread rice-wheat cropping pattern and crop damage due to high temperatures under late planting condition has become an important factor limiting wheat yield [4].

Bangladesh furnishes a good example of this process where wheat is grown in under hot and humid climate and in a short winter. Wheat is the second most important cereal crop next to rice in Bangladesh. Currently, wheat is grown about 0.706 million hectares with a production of 1.50 million tons [5].The national average of wheat yield is about $2 \mathrm{t} / \mathrm{ha}$ in Bangladesh which is about $50 \%$ lower than the potential yield of some released varieties. The yield gap between the potential and the national average is associated with many limiting factors of which high temperature stress is the vital factor [6]. About $80-85 \%$ of wheat in Bangladesh is grown after transplanting aman rice following rice-wheat cropping system of which $60 \%$ of area is planted lately due to in harvesting of rice[7]. Thus the crop frequently encounters high temperature (mean air temperature $>26^{\circ}$ C) stress during the reproductive stage of growth causing significant yield reduction. This problem will be further increased due to global warming. Such global warming would push the wheat cultivation further into heat stressed environment in future and may cause further yield reduction from the present yield level. Supra-optimal temperature during grain filling in the field associated with acceleration of phasic development [8], accelerated senescence [9], reduction of photosynthesis [10], increase in respiration and inhibition of starch synthesis in the growing kernel [11].The net effect of heat stress at the reproductive stage is to lower the kernel weight due to reduced grain filling period, grain filling rate or combined effect of both [12]. High temperature during grain filling stage has adverse effects on bread making quality [13].

In spite of low yield of wheat due to late planting postanthesis heat stress, cultivation of wheat cannot be avoided. Because the increasing demands of wheat and irrigation dependent Boro rice cultivation may need to be replaced in future by partially or non-irrigated wheat cultivation to overcome arsenic problem. Therefore, effort to be made to minimize the late planting yield reduction by screening or developing heat tolerant wheat varieties. In this study, effect of heat stress on growth of wheat genotypes was analyzed.

\section{MATERIALS AND METHODS}

\subsection{Location}

The experiment was conducted in the research farm of Crop physiology and Ecology Department, Hajee Mohammad Danesh Science and Technology University, Dinajpur, Bangladesh during the period from November to April of 2011-12 and 2012-2013.

\subsection{Materials}


For conducting the present investigation eight genotypes viz. Prodip, BARI Gom-25, BARI Gom-26, BAW-1143, BAW-1146, BAW-1147, BAW-1148 and Pavon-76, was used as experimental materials.

\subsection{Experimental design}

The experimental design was a split plot with three sowing dates. Three main plots were considered as treatment plots. Each main plot was subdivided into three replication plots each of $4 \times 2.5 \mathrm{~m}^{2}$ containing all the eight genotypes assorted randomly.

\subsection{Cultivation procedure}

Seeds were sown on 27 November (Normal), 17 December (Late) and 7 January (Very late). Three irrigation was applied at tillering, heading and grain filling stage.

\subsection{Measurements of growth}

In each year, there were 9,8 and 8 harvests for normal, late and very late growing conditions, respectively with equal intervals of 10 days and the first harvest was taken at 20 days after sowing (DAS). At each harvest, the plants were cut off at the ground level and the tops were separated into leaves, stem and panicle (if present).The harvested plants parts were kept in an electrical oven (Model -E28\# 03-54639, Binder, Germany) at about at $70^{\circ} \mathrm{C}$ for 72 hours and the dry weights of these plant parts were taken by an electrical balance (Model-AND EK-300i) and expressed in grams. Leaf area was determined as function of length maximum width $\times 0.75$ [14]. Dry weights of all the fractions were added to estimate total dry matter produced per unit land area.

\subsection{Growth Attributes}

Both the harvest interval method (classical technique) was followed to determine different growth attributes. From the dry weight of different plant parts and leaf area data, the following growth attributes were calculated between two successive harvests according to the classical technique of growth analysis [15].

1. Leaf area index (LAI) $=\frac{\text { Leaf area }}{\text { Ground area }}$

2. Crop growth rate $(C G R)=\frac{W_{2}-W_{1}}{t_{2}-t_{1}}$

3. Net assimilation rate

$$
(N A R)=\frac{\left(W_{2}-W_{1}\right)\left(\log _{e} L A_{2}-\log _{e} L A_{1}\right)}{\left(L A_{2}-L A_{1}\right)\left(t_{2}-t_{1}\right)}
$$

4. Leaf

area

duration

$$
(L A D)=\frac{\left(L A_{2}+L A_{1}\right)\left(t_{2}-t_{1}\right)}{2}
$$

Where, $\mathrm{W}_{2}$ and $\mathrm{W}_{1}$ are the total dry weights, $\mathrm{LA}_{2}$ and $\mathrm{LA}_{1}$ are the total leaf area per plant at $\mathrm{t}_{2}$ and $\mathrm{t}_{1}$, the later and the former harvest, respectively.

\subsection{Total Dry Matter (TDM)}

Influence of sowing time on total dry matter (TDM) of different wheat genotypes at different days after sowing (DAS) is shown in Figures 1.1 for 2011-12 and 1.2 for 2012-13. TDM increased slowly up to 50 DAS and then increased rapidly with the advancement of growing period of all the genotypes for both the years. At normal growing condition, all the genotypes produced higher TDM compared to late and very late growing heat stress condition. In second year (2012-13) all the genotypes produced higher TDM compared to the first year (201112) at each growing time due to lower temperature. Each growing conditions the heat tolerant genotype BAW-1143 produced the highest TDM whereas the heat sensitive genotype Pavon-76 obtained the lowest TDM at all the DAS. Genotypes BARI Gom -25, BARI Gom -26 and Prodip were intermediate producer of TDM. The moderate heat tolerant genotypes BAW-1146, BAW-1147 and BAW-1148 produced higher TDM than Pavon-76 but lower than those of the heat tolerant genotypes.

\subsection{Leaf Area Index (LAI)}

The effect of growing conditions on leaf area index (LAI) of eight wheat genotypes at different stages of growth is shown in Figures 2.1 for first year (2011-12) and 2.2 for second year (2012-13). LAI of all the genotypes for each the growing conditions started from a lower value and reached their peak at a certain stage of growth and declined thereafter in each years. At optimum sowing time (normal growing condition) all the genotypes showed higher LAI compared to late and very late sowing high temperature growing condition. At normal growing all the genotypes reached their highest value of LAI at 70 DAS, whereas for late and very late growing condition it was 60 DAS [23].They observed that leaf area of wheat genotypes decreased with late sowing. The decline in LAI following the flag leaf stage might be ascribed by aging of leaves, leaf senescence and thermal stress at later growth stages [24].

At normal growing condition heat tolerant genotype BAW-1143 showed the highest LAI at all the growth stages except at 20 DAS which was closely followed by HT genotypes BARI Gom -25, BARI Gom-26 and Prodip. At 70 DAS, BAW-1143 had the highest value of 
LAI. In this sowing time, heat sensitive genotype Pavon76 had the lowest LAI which was closely followed by other MHT genotype BAW-1146, BAW-1147 and BAW1148.

At late and very late growing condition the HT genotype BAW-1143 attained the highest LAI at all the growth stages.

\subsection{Crop Growth Rate (CGR)}

Crop Growth Rate (CGR) indicates the amount of dry matter accumulation rate per unit land area which the most significant term of analysis in field.

The effect of sowing time on crop growth rate of different wheat genotypes at successive days after sowing is presented in Figures 3.1 for 2011-12 and 3.2 for 2012-13. The CGR being controlled by canopy, photosynthesis and respiration, so, it is considered more meaningful function of crop growth. In each growing conditions, starting from a lower value, CGR of all the genotypes reached a certain peak and thereafter declined. At normal growing condition, all the genotypes in both the years attained their highest CGR at 70-80 DAS, whereas at late and very late growing condition it was at 60-70 DAS. In normal growing condition, all the genotypes showed higher CGR compared to late and very late growing condition. Heat tolerant genotypes BAW-1143 attained the highest CGR value at all the DAS in each sowings except at 90-100 DAS. At 90-100 DAS, HT genotype BAW-1143 had the highest CGR. Other MHT genotypes e.g. BARI Gom-25, BARI Gom -26 and Prodip closely followed BAW-1143. Whereas, heat sensitive genotype Pavon-76 showed the lowest CGR in all respects which was closely followed by the other HS genotypes BAW-1146, BAW-1147 and BAW-1148.

\subsection{Net Assimilation Rate (NAR)}

Net assimilation rate (NAR) of different wheat genotypes at different growth condition is presented in Figures 4.1 for 2011-12 and 4.2 for 2012-13. NAR in all the genotypes for both the growing conditions started from a lower value and reached their peak at certain stage of growth and thereafter declined slowly. At normal growing condition, all the genotypes attained their highest NAR at 70-80 DAS, whereas in late and very late sowing heat stress condition it happened at 60-70 DAS. At very late sowing heat stress condition, NAR was higher up to 6070 DAS compared to normal sowing for all the genotypes. The figure showed that pattern of NAR was depended on the phenological stages at all sowing times. At normal growing condition, BAW-1143 attained the highest NAR at 70-80 DAS which was closely followed by, BARI Gom -25, BARI Gom -26 and Prodip . At this growth stage (70-80 DAS), BAW-1146, BAW-1147, BAW-1148 and Pavon-76 had the lowest NAR value. But in late and very late growing condition Pavon-76 attained the highest NAR at 60-70 DAS. In this conditions (late and very late sowing), Pavon-76 showed the lowest NAR at that growth stage (60-70 DAS).

\subsection{Leaf Area Duration (LAD)}

The effect of sowing time on Leaf Area Duration (LAD) of different genotypes of wheat at the different days after sowing (DAS) is shown in Figures 5.1 for the year 201112 and 5.2 for 2012-13. In all the genotypes for both the sowings and years, LAD started from a lower value and reached to their peak at a certain DAS and declined thereafter. At normal growing condition of both the years, all the genotypes reached their highest value of LAD at 70-80 DAS, whereas for late and very late growing condition it was 60-70 DAS. There existed similarities between two years growth pattern of LAD of all the genotypes. In both the years, at normal growing condition all the genotypes attained significantly higher LAD values compared to their respective late and very late growing conditions.

At normal growing condition of both the years, the HT genotype BAW-1143 showed the highest LAD at all the growth stages which were followed by Prodip, BARI Gom-25and BARI Gom-26. Whereas, the HS genotype Pavon-76 attained the lowest LAD values at all the DAS. Genotypes BAW-1146 and BAW-1147 was intermediate performer in LAD.

In both the years, at late and very late growing condition again HT genotype BAW-1143 attained the highest LAD at all the growth stages except at 20-30 DAS which was followed by Prodip, BARI gom-25 and BARI gom-26. At 20-30 DAS, the HT genotype BAW-1143 had the highest LAD, whereas HS genotype Pavon-76 attained the lowest LAD at all the DAS which was closely followed by other genotype BAW-1148.

\section{DISCUSSIONS}

In this study, the maximum value of total dry matter was obtained for the maximum value of leaf area index in the first planting date or the least duration of comforting with terminal heat stress. Delayed sowing of wheat resulted in the reduction of total dry weight [16]. There were vitiations in TDM compared to late sowing (December) [17]. The rapid increased in total dry matter at the later stages of growth was due to the development of considerable number of late tillers [18]. After 90 days in case of normal and late sowing and 80 days in case of very late sowing until harvest time, it decreased due to hastened leaf senescence and decreased of leaf area index[19].

The appropriate sowing plants produced higher TDM due to longer duration of vegetative phase. The decreased in 
dry matter accumulation with the increase of terminal heat stress indicates the unfavourable response of wheat genotypes to terminal heat stress. It is perhaps related to the decreased of the photosynthesis activity that has led to decreased in dry matter accumulation. Dry matter accumulation decreased due to a decreased in leaf number, leaf area index and accumulation in leaf senescence in wheat [19].

It is perhaps related to a relationship between leaf area index and accumulation of dry matter, especially when wheat encounters to heat stress $[12,20]$. Wheat yield and dry matter accumulation decreased with high temperature in during most reproductive stages when wheat enters the grain- filling period [22].

In the present study, LAI of all wheat genotypes for both the growing conditions started from a lower value and reached highest level at a certain stage of growth and declined thereafter. Leaf area index is a growth indicators used as a photosynthetic system measurement. LAI is related to the biological and economic yields and increase in LAI causes higher yield [25]. Under late sown condition, minimum LAI was recorded which might be due to sub-optimum temperature during the vegetative growth phase, as leaf development greatly depends on the prevailing temperature [26]. Thus in response to an increase in temperature, the leaf area remains too small to support the required growth of the seedling. In addition the low temperature slows down the rate of leaf initiation (Warrington \& Kanemasu 1983), which may decrease the LAI. Leaf area index decreased due to increasing aging of leaves, hastens leaf senescence, shading and competition between plants for light and other resources, especially, when wheat encounters high temperatures. Increasing leaf area index is one of ways of increasing the capture of solar radiation within the canopy and production of dry matter [24]. Leaf area index was reduced differently in different wheat genotypes in response to high temperature stress $[27,28]$.

In the present study CGR was found higher for normal growing condition compared to late and very late growing condition. The comparatively higher CGR values at anthesis stage could be described by favourable temperature. Higher CGR for normal growing condition was due to higher production of dry matter owing to greater LAI [29]. Among the genotypes the heat tolerant group (BAW-1143, BARI Gom -25, BARI Gom -26 and Prodip) had higher CGR than MHT genotypes (BAW1146, BAW-1147, BAW-1148) and heat sensitive genotype Pavon-76 in all the DAS for both the growing conditions. Highest CGR for optimum sowing compared to others genotypes and decreased with any delay in sowing [17]. However, CGR is regarded as the most meaningful growth function, since it represents the net result of photosynthesis, respiration and canopy temperature and canopy area interactions [29]. Maximum growth rate confirmed to the beginning of reproductive growth, which decreases with plant's higher maturity due to growth ending, leave's losses and withering. The great variation of CGR among genotypes indicates the problems of less efficient photosynthetic activity, their source to sink relation and managing of leaf area through plant population [30].

NAR increased slowly at the early stages of growth but at the later stages it increased sharply $[17,31,32]$. The rapid increase in NAR at the later stages may be due to increase ear photosynthesis in addition of increased photosynthesis of the developed leaf. In the present study, higher NAR values were observed in the late growing condition up to 60-70 DAS compared to the normal growing condition for all the genotypes.

It is due to plants of late growing condition passed through comparatively lower temperature at the early vegetative stages. Higher NAR was at the delayed sowing in wheat [17]. The maximum NAR figure at flag leaf can be attributed by higher leaf area[33]. In the present work, among the genotypes heat tolerant groups (BAW1143, BARI Gom -25, BARI Gom -26 and Prodip) showed higher NAR than those of MHT genotypes (BAW-1146, BAW-1147, BAW-1148) and HS genotype Pavon-76 at all stages of growth in the normal growing condition. This is due to genetic characters of genotypes.NAR found variation among genotype and influenced by temperature [30].

In this study, it was observed that the flag leaves of some of the genotypes expanded lately but they senesced at the same time with others where flag leaves expanded earlier resulting a shorter leaf area duration in those genotypes. Leaf area duration (LAD) of all the genotypes showed essentially similar pattern to their LAI in both the years. Higher LAD was found in the normal growing condition compared to late growing condition in both the years. Heat tolerant genotypes (BAW-1143, BARI gom-26, BARI gom-25 and Prodip) attained higher LAD compared to heat sensitive genotype Pavon-76 in each growing conditions of every year. Optimum sowing (mid November) of wheat genotypes showed higher LAD compared to late sowing (mid December) and some wheat genotypes attained comparatively higher LAD than those of others[17]. Optimum temperature $\left(20^{\circ} \mathrm{C}\right)$ at the vegetative stage enhanced the leaf initiation and leaf emergence for a longer period as revealed in the normal growing condition in wheat[34]. This duration decreased with delay in sowing prevailed by lower temperature at the early vegetative stage as found in the late growing condition. 


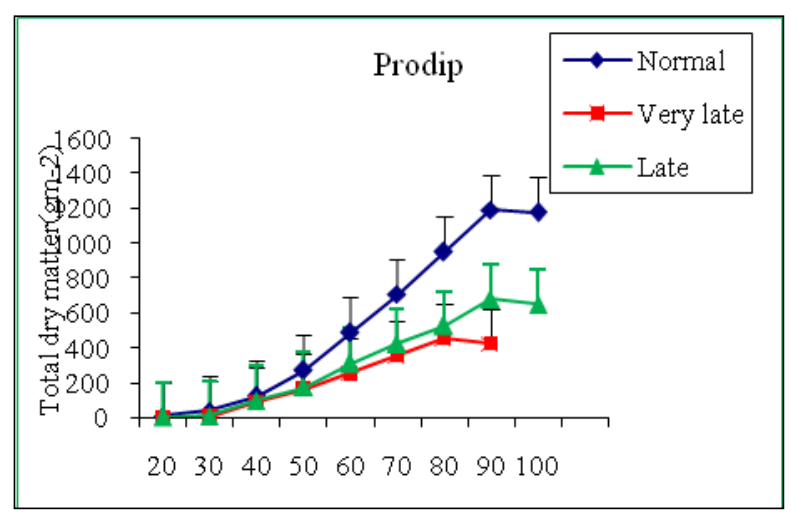

\section{FIGURES}
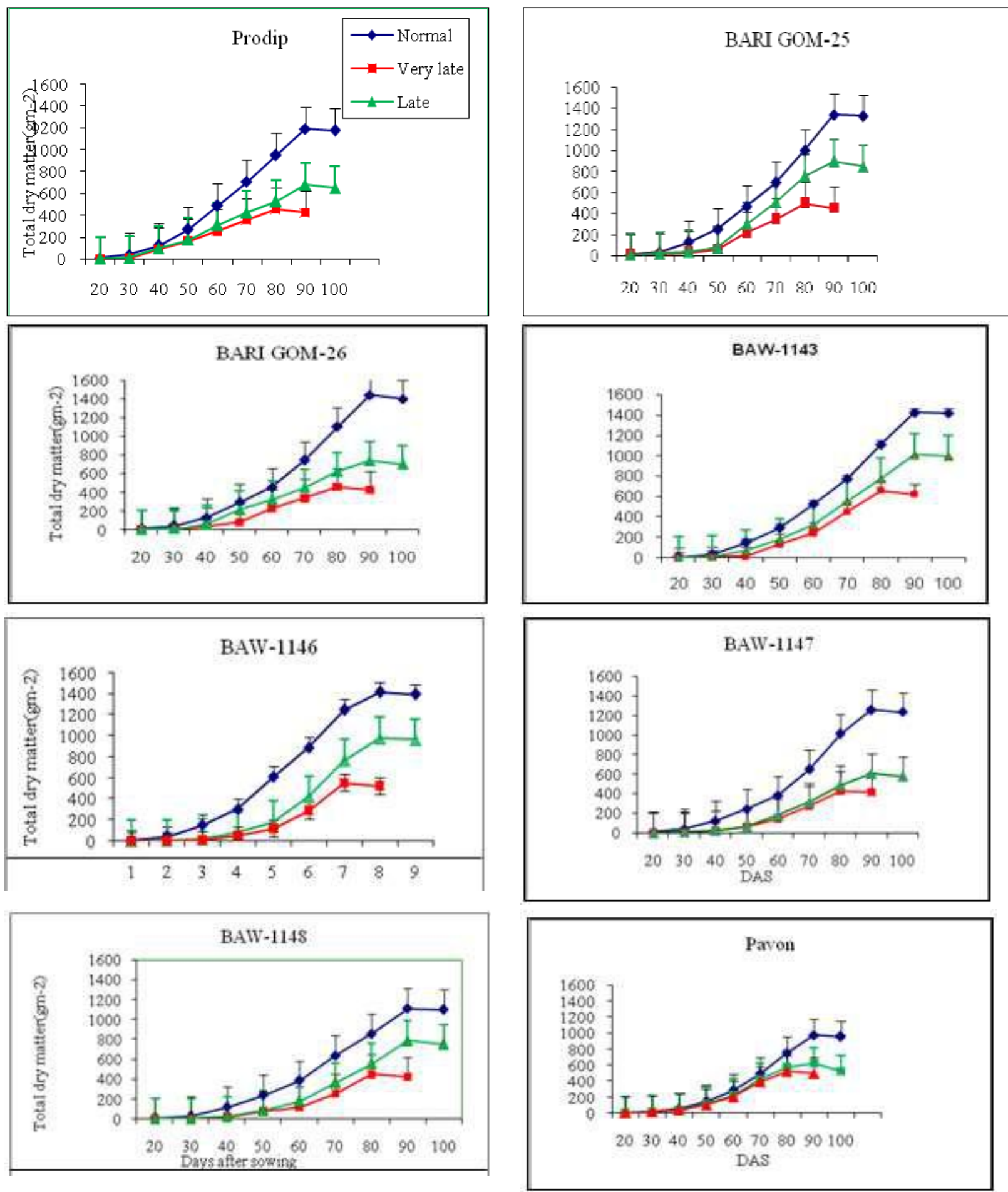

Fig.1.1: Effect of sowing time on total dry matter (TDM) of eight wheat genotypes at different days after sowing from original values (2011-12). Vertical bars indicate \pm SE value. 


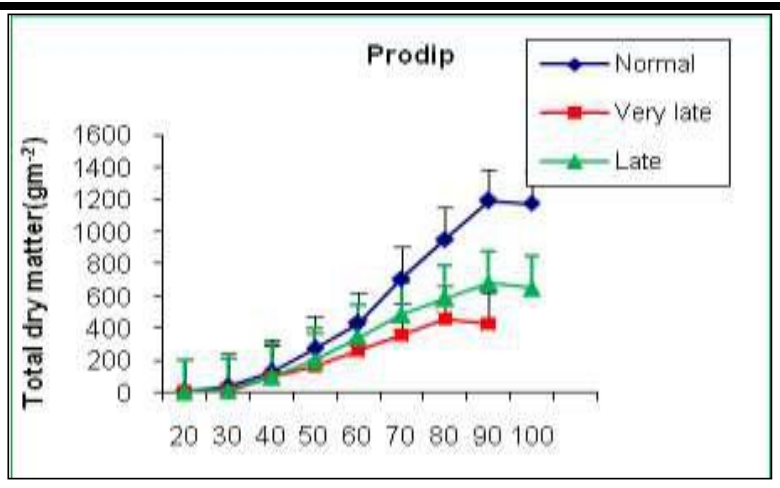

BARI Gom-25
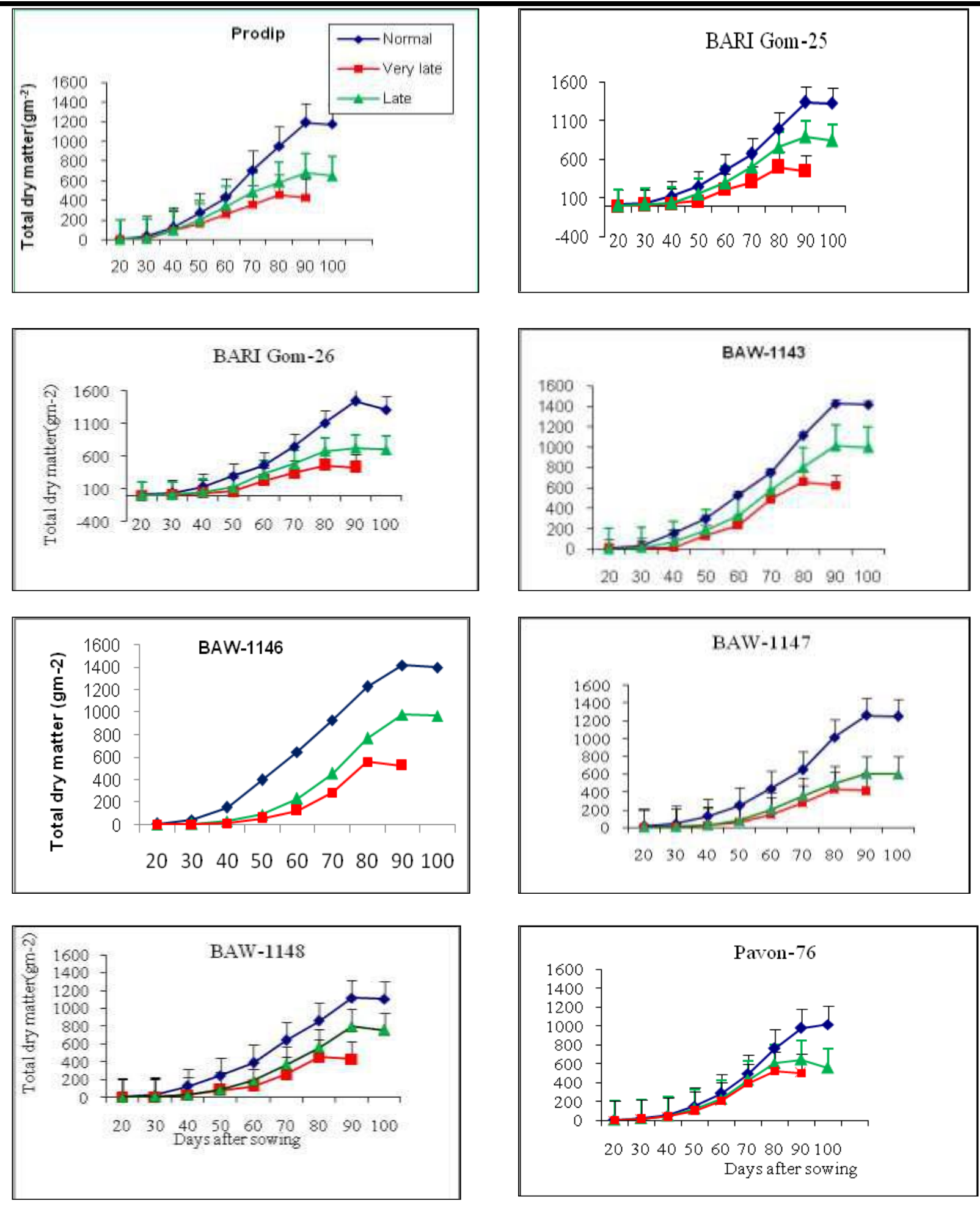

Fig.1.2: Effect of sowing time on total dry matter (TDM) of eight wheat genotypes at different days after sowing from original values (2012-13). Vertical bars indicate \pm SE value. 

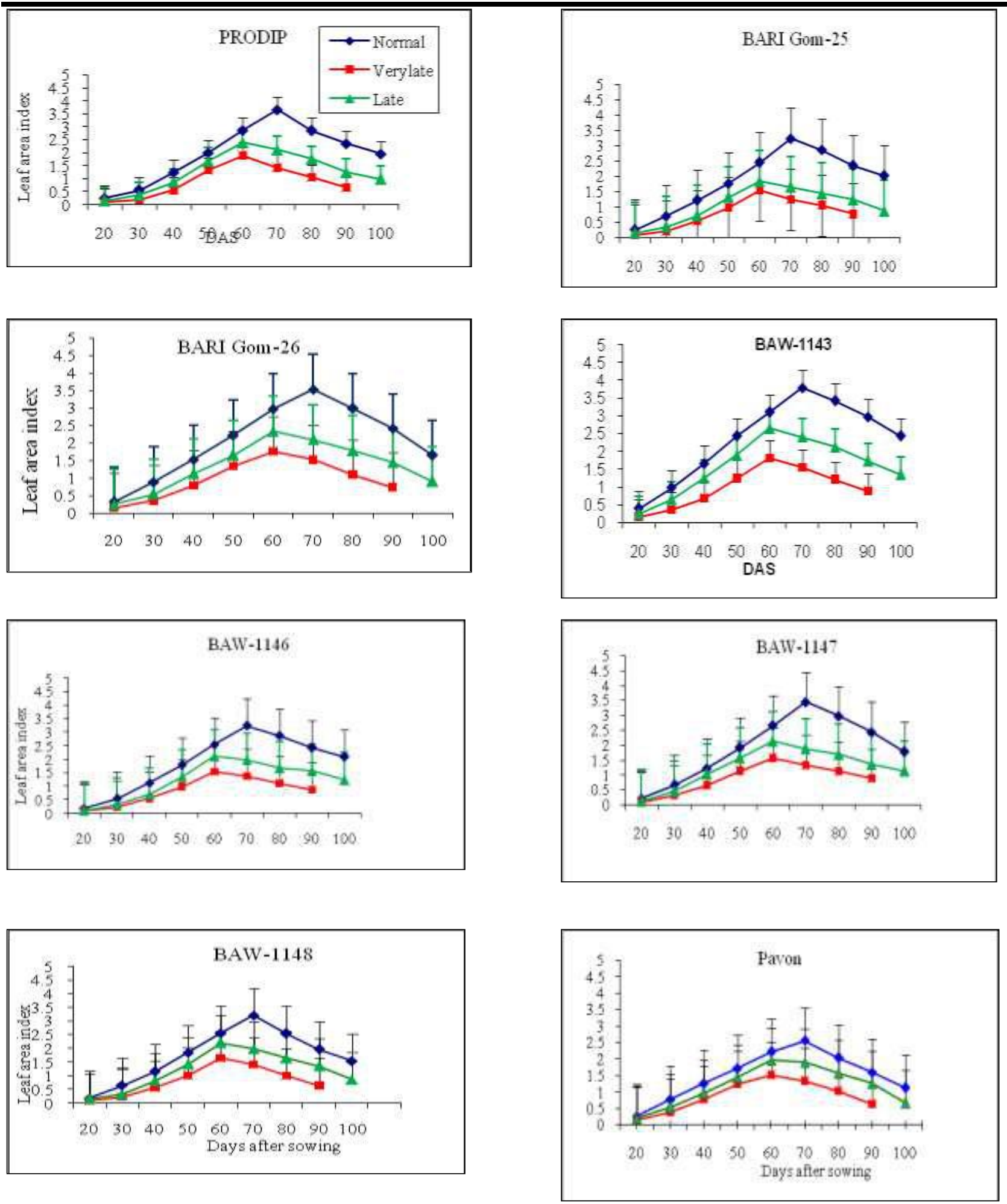

Fig.2.1: Effect of sowing time on Leaf area index (LAI) of eight wheat genotypes at different days after sowing from original values (2011-12). Vertical bars indicate \pm SE value. 

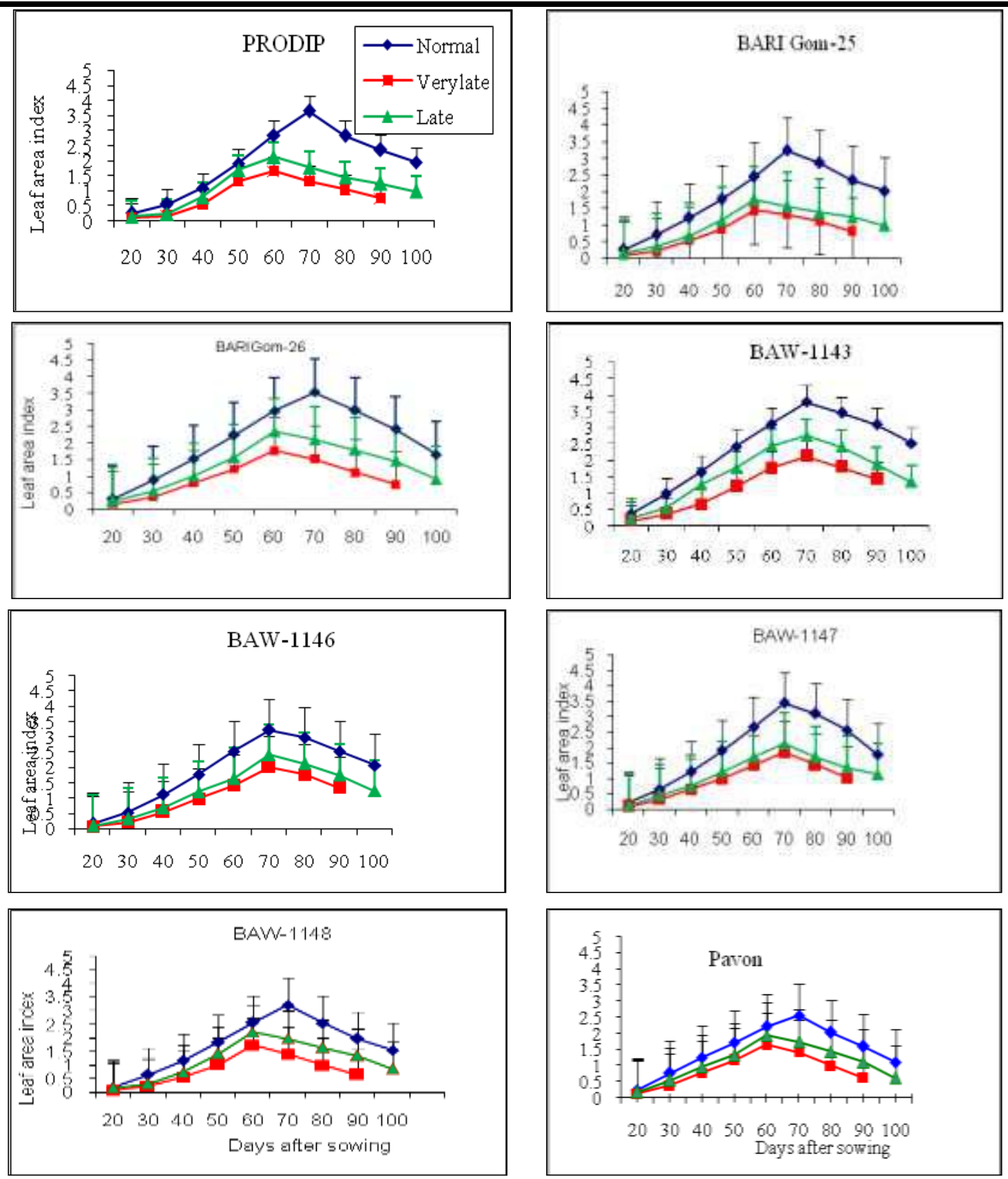

Fig.2.2: Effect of sowing time on leaf area index (LAI) of eight wheat genotypes at different days after sowing from original values (2012-13). Vertical bars indicate \pm SE value. 

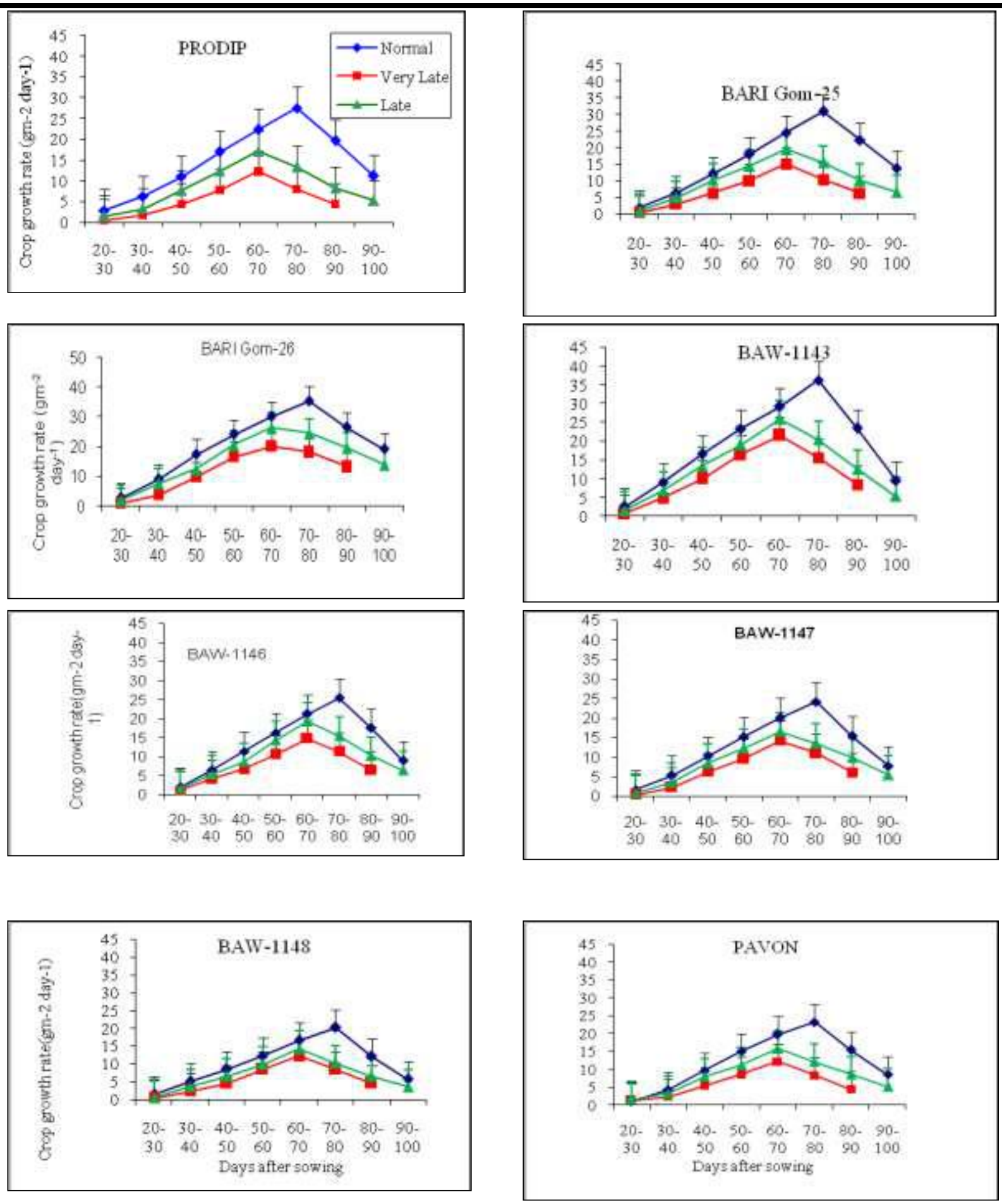

Fig.3.1: Effect of sowing time on Crop growth rate (CGR) of eight wheat genotypes at different days after sowing from original values (2011-12). Vertical bars indicate + SE value. 

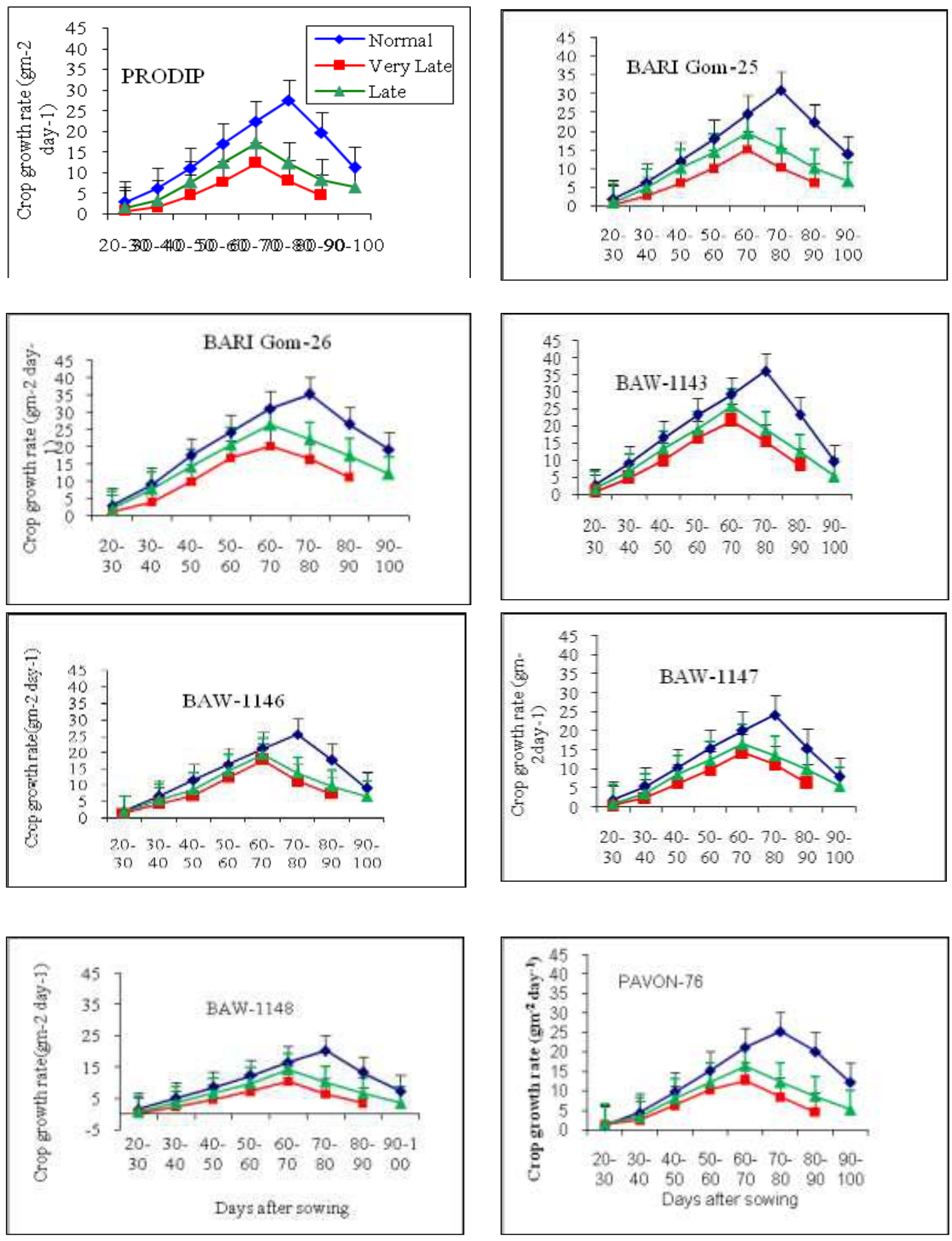

Fig.3.2: Effect of sowing time on Crop growth rate (CGR) of eight wheat genotypes at different days after sowing from original values (2012-13). Vertical bars indicate \pm SE value. 

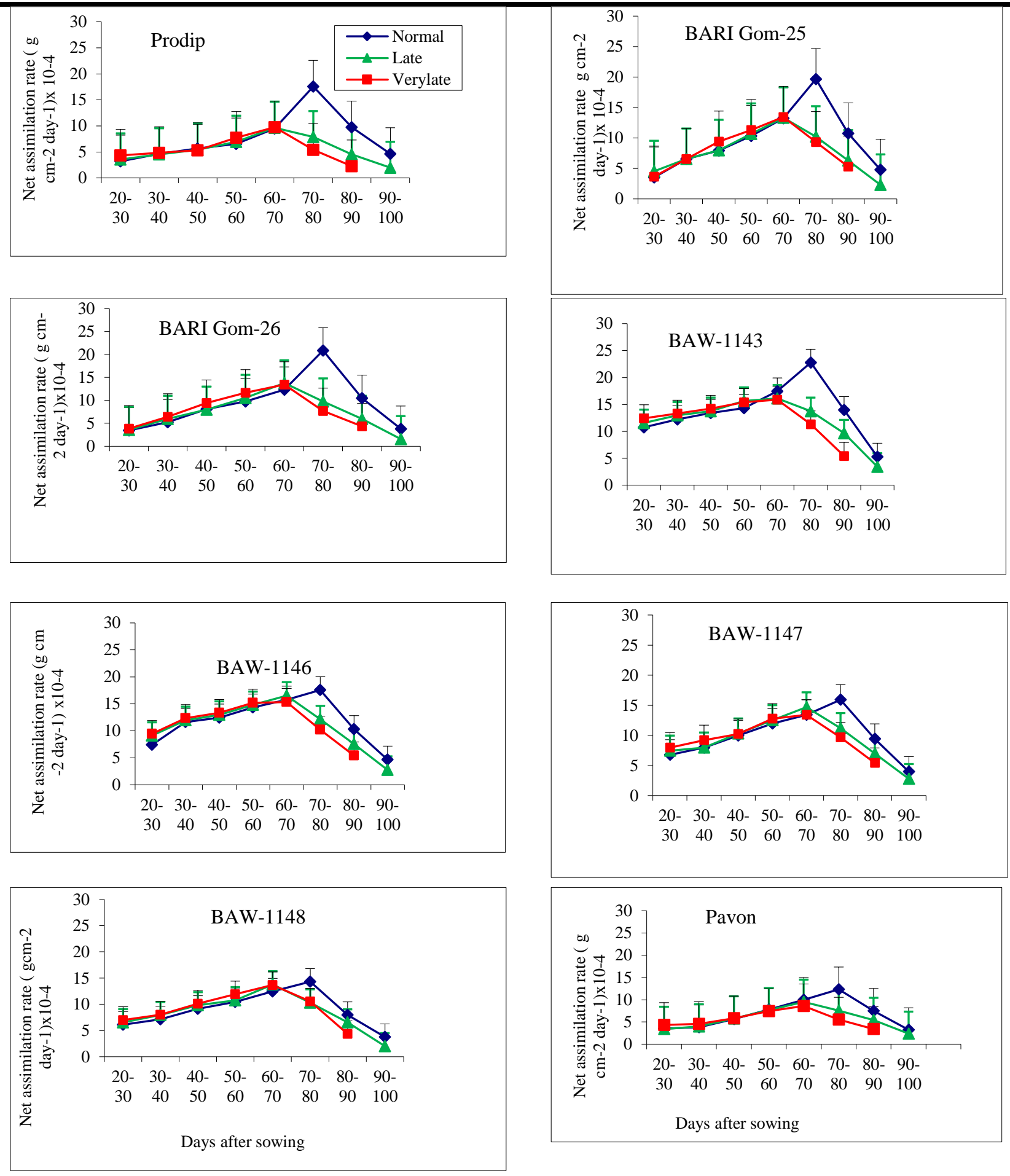

Fig.4.1: Effect of sowing time on Net assimilation rate (NAR) of eight wheat genotypes at different days after sowing from original values (2011-12). Vertical bars indicate \pm SE value. 

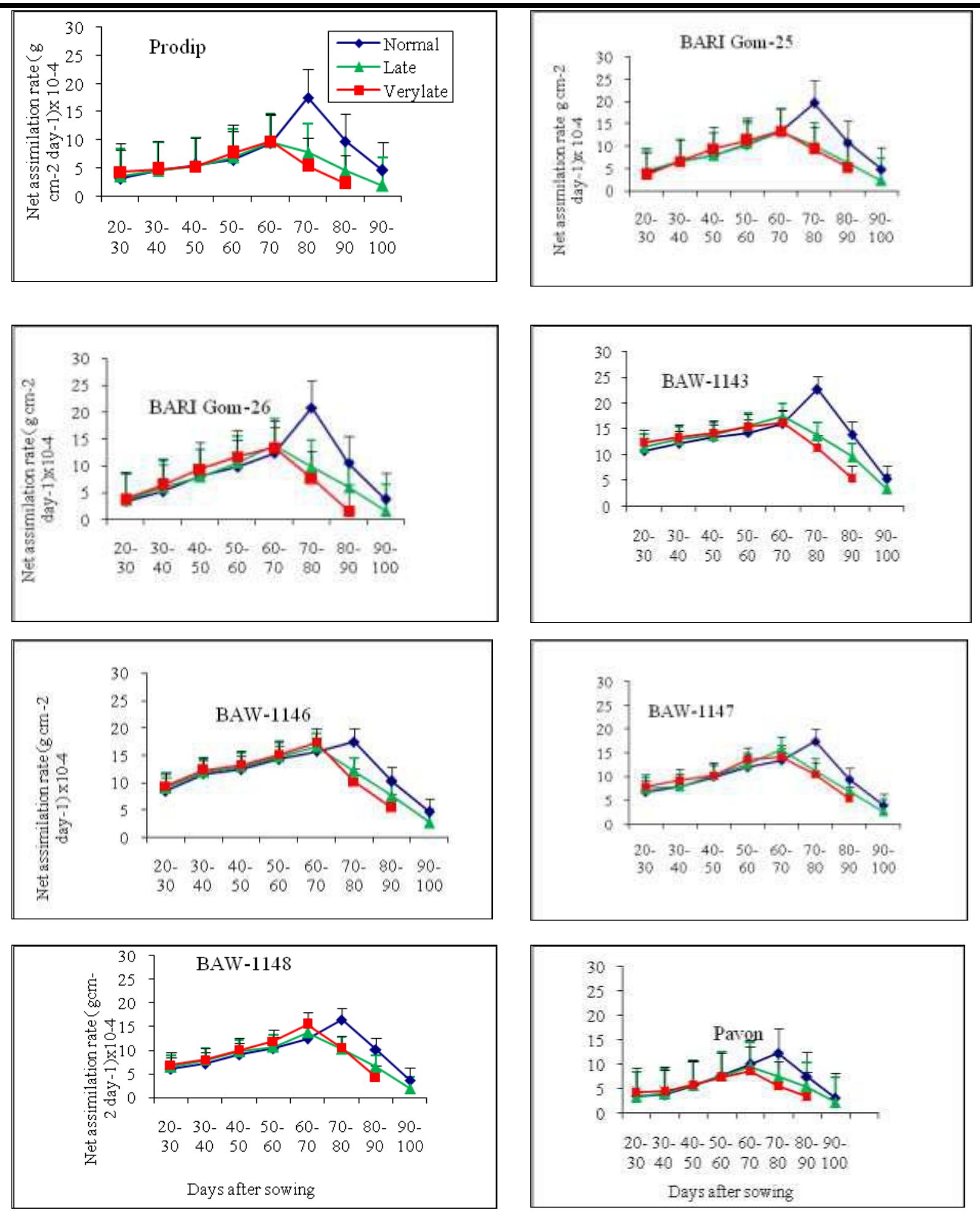

Fig.4.2: Effect of sowing time on Net assimilation rate (NAR) of eight wheat genotypes at different days after sowing from original values (2012-13). Vertical bars indicate \pm SE value. 

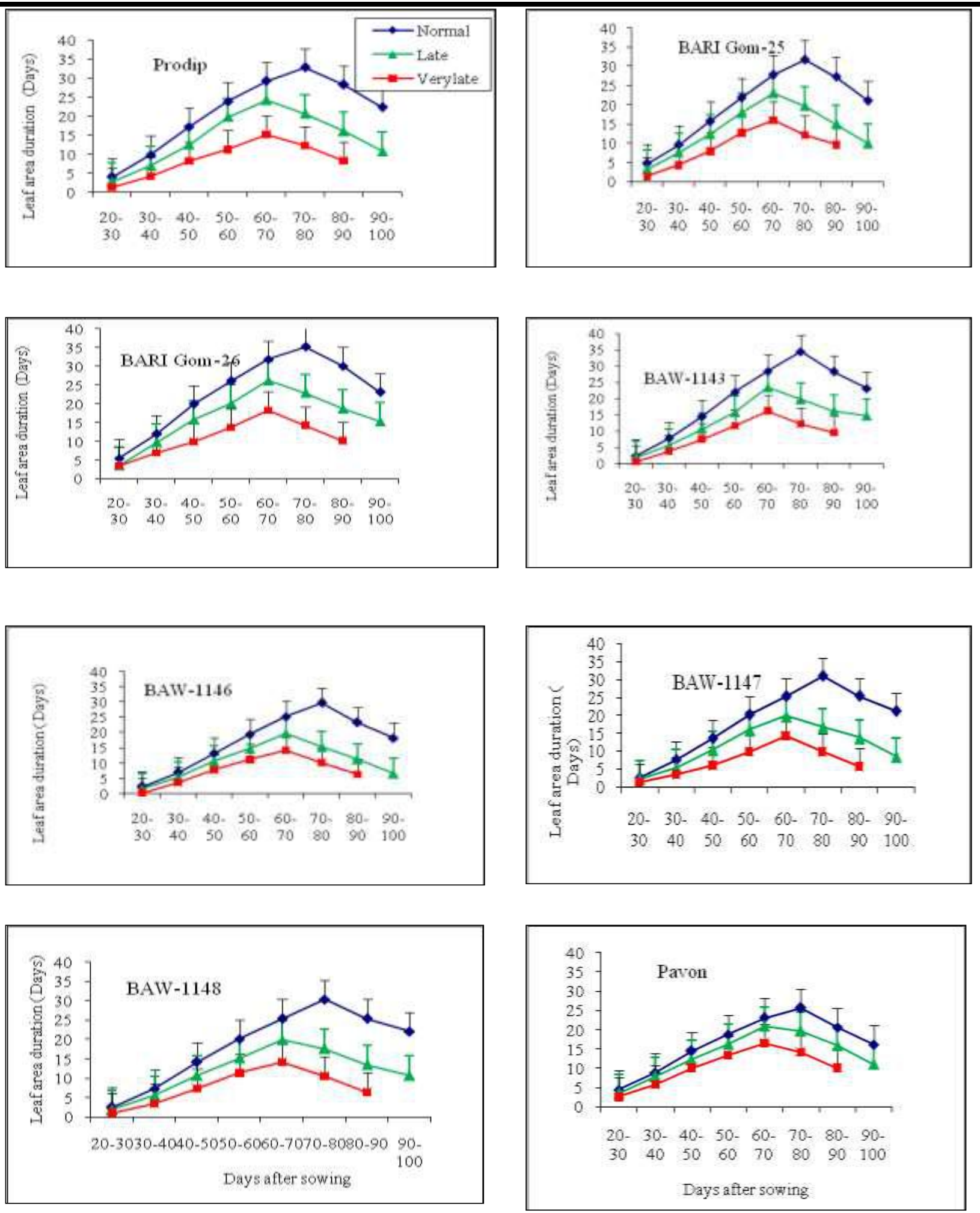

Fig.5.1: Effect of sowing time on Leaf area duration (LAD) of eight wheat genotypes at different days after sowing from original values (2011-12). Vertical bars indicate \pm SE value. 

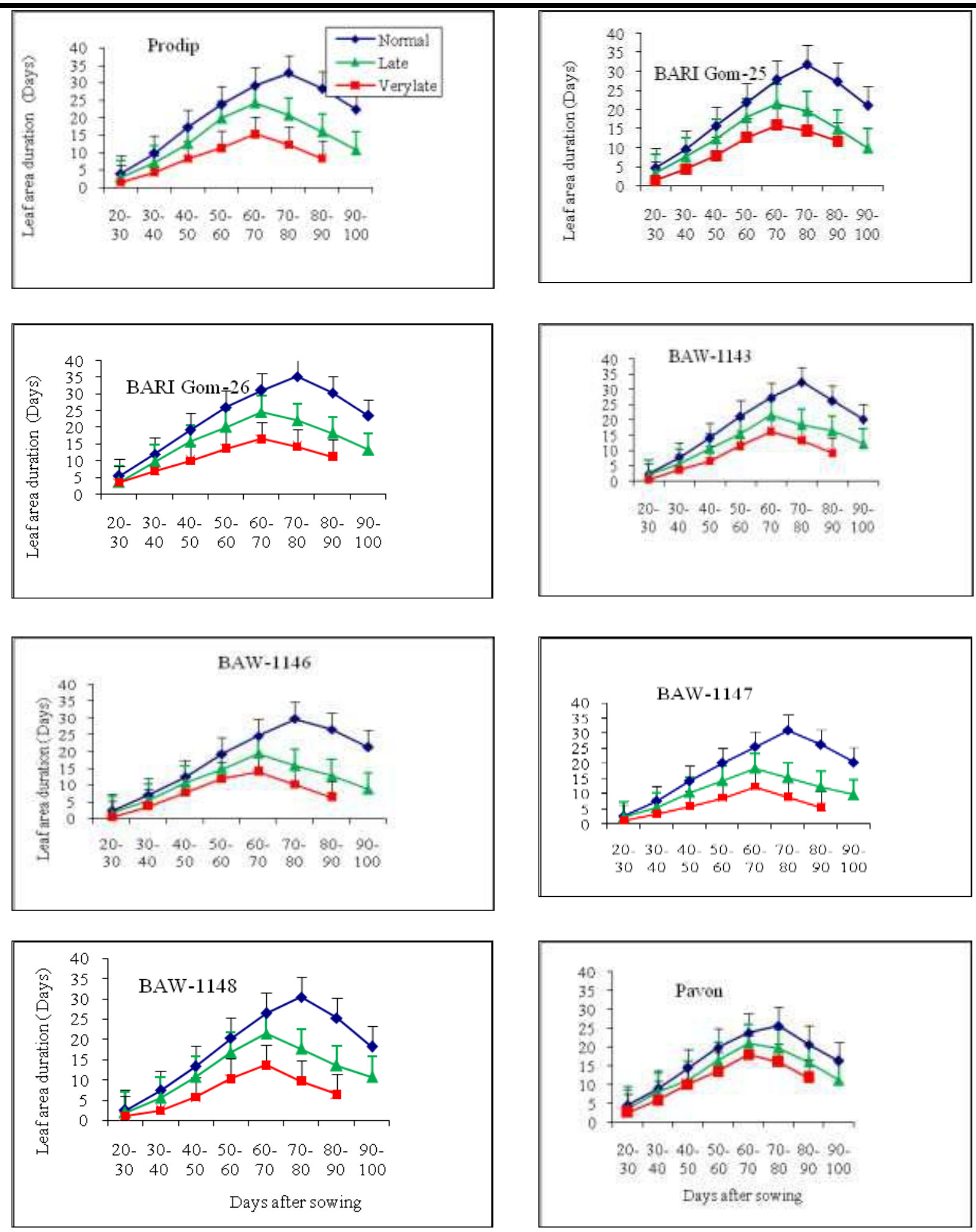

Fig.5.2: Effect of sowing time on Leaf area duration (LAD) of eight wheat genotypes at different days after sowing from original values (2012-13). Vertical bars indicate \pm SE value.

\section{CONCLUSION}

Total dry matter (TDM), Leaf area index (LAI), crop growth rate (CGR), net assimilation rate (NAR) increased slowly at initially stage and increased rapidly with the advancement of growing period of all the genotypes for both the years. At normal growing condition, all the genotypes produced higher value compared to late and very late growing heat stress condition. In second year (2012-13) all the genotypes produced higher value of these compared to the first year (2011-12). Each growing 
conditions the heat tolerant genotype BAW-1143 produced the highest value. Whereas, the heat sensitive genotype Pavon-76 obtained the lowest value at all the DAS. Genotypes BARI Gom -25, BARI Gom -26 and Prodip were intermediate producer. The moderate heat tolerant genotypes BAW-1146, BAW-1147 and BAW1148 produced higher value than Pavon-76 but lower than those of the heat tolerant genotypes. In all the genotypes for each sowings and both years, LAD started from a lower value and reached to their peak at a certain DAS and declined thereafter. At normal growing condition of both the years, all the genotypes reached their highest value of LAD at 70-80 DAS, whereas for late and very late growing condition it was 60-70 DAS. In both the years, at normal growing condition all the genotypes attained significantly higher LAD values compared to their respective late and very late growing conditions.At normal growing condition of both the years, the HT genotype BAW-1143 showed the highest LAD at all the growth stages which were followed by Prodip, BARI gom-25and BARI gom-26. Whereas, the HS genotype Pavon-76 attained the lowest LAD values at all the DAS. BAW-1146 and BAW-1147 was intermediate performer in LAD. In both the years, at late and very late growing condition again HT genotype BAW-1143 attained the highest LAD at all the growth stages which was followed by Prodip, BARI Gom-25 and BARI Gom-26. At 20-30 DAS, the HT genotype BAW-1143 had the highest LAD, whereas HS genotype Pavon-76 attained the lowest LAD at all the DAS which was closely followed by other genotype BAW-1148.

\section{REFERENCES}

[1] Chowdhury, S.I., Wardlaw,I.F.(1978):The effect of temperature on kernel development in cereals. Australian Journal of Agricultural Research 29:205223.

[2] Stone, P. J., Nicolas, M. E. (1994): Wheat cultivars vary widely in their responses of grain yield and quality to short periods of post anthesis heat stress. Australian Journal Plant Physiology 21: 887-900.

[3] Ruwali, H., Bhawsar, R.C. (1998): Effect of high temperature on grain development of wheat under late sown irrigated conditions. In: Wheat research needs beyond 2000AD, pp. 68-69. Proc. Int. Conf., Karnal.

[4] Zong-Hu, H., Rajaram, S. (1994): Differential responses of bread wheat characters to high temperature. Euphytica 72:197-203.

[5] BBS, (2012):Statistical Year Book of Bangladesh. Statistics Division, Ministry of Planning.Govt. of the Peoples' Republic of Bangladesh, Dhaka.
[6] Ahmed, S. M., Meisner, C. A. (1996): Wheat research and development in Bangladesh. Bangladesh Australian wheat improvement project and CIMMYT, Dhaka.pp525.

[7] Badaruddin, M., Saunders, D. A., Siddique, A. B., Hossain , M. A., Ahmed ,M.O., Rahman, M. M., Parveen, S. (1994): Determining yield constraints for wheat production in Bangladesh. In: Wheat in heat stress environments; irrigated, dry

areas and rice- wheat farming system, D.A. Saunders and G.P. Hattel (Eds), pp. 265-271. CIMMYT, Mexico D.F.

[8] Shpilar, L., Blum, A.(1991): Heat tolerance for yield and its components in different wheat cultivars. Euphytica .51: 257-263.

[9] Reynolds, M. P., Balota, M. M., Delgado, I. B., Amani, I., andFischer, R. A.(1994): Physiological and morphological traits associated with spring wheat yield under hot, irrigated conditions. Aust. J. Plant Physiol. 21:717-730.

[10] Al- Khatib, K., Paulsen, G. M. (1999):. High temperature effect on photosynthetic processes in temperate and tropical cereals. Crop Sci.39:119-125.

[11] Rijvan, A. H. G. (1986): Heat inactivation of starch synthesis in wheat endosperm. Plant Physiol. 81: 448-453.

[12] Tashiro, T., Wardlaw, I. F. (1989): A comparison of the effect of high temperature on grain development in wheat and rice. Ann. Bot. 64: 59-65.

[13] Randle ,P.J., Moss, H.J. (1990): Some effects of temperature regimes during grain filling on wheat quality. Aust. J. Agric. Res. 41: 603-17.

[14] Mossad, M., Ortiz-Ferrara, G., Mahalakshmi, V., Fischer, R.A. (1995): Phyllochron response to vernalization and photoperiod in spring wheat. Crop Sci. 35: 168-171.

[15] Radford, P. J.(1967).Growth analysis formulae- their use and abuse. Crop Sci. 7: 171-175.

[16] Kumar, R., Sharma, S. N. (1999): Effect of nitrogen on dry matter and nutrient accumulation pattern in wheat (Triticum aestivum L.) under different dates of sowing. Indian Journal of Agronomy. 44(4): 738744.

[17] Haque, M. M. 2000.Physiological analysis of yield of wheat (Triticum aestivum L.) in relation to sowing date. Ph. D. thesis. University of Rajshahi, Bangladesh.

[18] Talukder, M. S. U. 1987. Growth and development of wheat as affected by soil moisture. Indian Journal of Agricultural Science. 57: 559- 564.

[19] Guttieri, M.J., Stark, J.C., Obrien, K. and Souza, E.2001. Relative sensitivity of spring wheat grain 
yield and quality parameters to moisture defecit. Crop Science.41:327-335.

[20] Warrington, I. J., Dustone, R. L., Green, L. M. (1977). Temperature effects at three development stages on the wheat ear. Aust. J. Agric. Res. 28: 1127.

[21] Tashiro, T. ,Wardlaw,I. F. (1989): A comparison of the effect of high temperature on grain development in wheat and rice. Annals of Botany. 64: 59-65.

[22]Zhong-hu, H., Rajaram, S. (1994):. Differential responses of bread wheat characters to high temperature, Euphytica .72: 197-203.

[23] Ashraf, M. Y., Bhatti,A. S. (1998). Effect of delay sowing on some parameters of photosynthesis in wheat (Triticum aestivum L.).Wheat information service. No.86: 46-48.

[24]Dalirie, M.S., Sharifi ,R.S. , Farzaneh ,S.(2010): Evaluation of yield, dry matter accumulation and leaf area index in wheat genotypes as affected by terminal drought stress. Not. Bot. Hort. Agrobot. Cluj, 38(1):182-186.

[25] Singh, P., Agrawal, M. and Agrawal, S.B..(2009(.Evaluation of physiological, growth and yield responses of a tropical oil crop (Brassica campestris L. Var.Ktranti) under ambient ozone pollution at varying NPK levels. Environmental pollution. 157:871-880.

[26] Warrington, I. J and Kanenasu, E. T. (1983): Corn growth response to temperature and photoperid II. Leaf-initiation and leaf-appreance rates. Agronomy Journal.5:755-761.

[27] Cao, W., Moss, D. N.(1989).Temperature effect on leaf emergence and phyllochron in wheat and barly. Crop Science.29, 1018-1021.

[28] Acevedo, E., Nachit, M.L.L. Ferrana, G. O. (1991): Effect of heat stress of wheat and possible selection tools for use in breeding for tolerance. In: D.A. Saunders (Ed), Wheat for non-traditional warm areas. pp 401- 420. CIMMYT, Mexico D.F.

[29] Haider, S.A.( 2007); Growth analysis in relation to sowing dates in four varieties of wheat: a functional: approach. Journal Life Earth Sci.2 (2):17-25.

[30] Hussain, I., Khan, M.A. and Khan,H. (2010). Effect of seed rates on the Agro-physiological traits of wheat. Sarhad Journal Agriculture. 26(2): 169-176.

[31] Saha, S. K., Paul,N. K. (1995): Growth of five wheat cultivars as affected by soil moisture. Journal of Biological Science. 3: 103-112.

[32] Nahar, N. and Paul,N. K. (1998):. Growth analysis of wheat genotypes under different soil moisture regimes. Bangladesh Journal of Agricultural Research.23: 54-57.
[33] Ahmed, M., Farooq, S.(2013): Growth and physiological responses of wheat cultivars under various planting windows. Journal of Animal and plant Science. 23 (5): 1407-1414.

[34] Samanta, S. C., Gaffer, M. A., Kamal, A. M. A., Samad,M. A. (1997): Growth and yield of prosomillet cultivars as influenced by sowing date. Bangladesh J.Agril. Sci. 24: 37-41. 